\title{
O CUSTO MARGINAL SOCIAL DA TRIBUTAÇÃO INDIRETA NO BRASIL: IDENTIFICANDO DIREÇÕES DE REFORMA
}

\author{
Rozane Bezerra de Siqueira* \\ José Ricardo Bezerra Nogueira ${ }^{\dagger}$ \\ Evaldo Santana de Souza ${ }^{\ddagger}$ \\ Diogo Baerlocher Carvalho $§$
}

\begin{abstract}
Resumo
Este artigo aplica o método desenvolvido por Ahmad \& Stern (1984) para calcular o custo marginal social da tributação para 27 grupos de bens, usando microdados da POF 2002-2003 e elasticidades-preço da demanda baseadas no Sistema Quase Ideal de Demanda (AIDS). As estimativas são apresentadas para diferentes hipóteses sobre o grau de aversão da sociedade à desigualdade. Os resultados indicam que alguns bens são fortes candidatos à redução de tributação (e outros, ao aumento de tributação) tanto por considerações distributivas quanto de eficiência. Porém, de forma geral, há um forte conflito entre os objetivos de equidade e de eficiência na reforma da tributação indireta no Brasil.
\end{abstract}

Palavras-chave: Tributos Indiretos; Reforma Tributária; Bem-Estar Social.

\begin{abstract}
This paper applies the method developed by Ahmad \& Stern (1984) to calculate the marginal welfare cost of taxation for 27 commodity groups using microdata from the POF 2002-2003 and price-elasticities of demand based on the Almost Ideal Demand System (AIDS). The estimates are presented for different assumptions about the society's degree of inequality aversion. The results suggest that some commodity groups are strong candidates to lower (and other groups, to higher) taxation both for distributional and efficiency reasons. However, in general, there is a strong conflict between equity and efficiency considerations in reforming the Brazilian indirect tax system.
\end{abstract}

Keywords: Indirect Taxes; Tax Reform; Social Welfare.

JEL classification: H21, H22, H23

\footnotetext{
* Universidade Federal de Pernambuco. E-mail: rozane_siqueira@yahoo.com.br

† Universidade Federal de Pernambuco. E-mail: jrbnogueira@yahoo.com.br

‡ Universidade Federal de Pernambuco. E-mail: ess@ufpe.br

$\S$ Universidade Federal de Pernambuco. E-mail: diogo.baerlocher@gmail.com
} 


\section{Introdução}

O tema de reforma tributária tem estado no centro do debate sobre políticas públicas no Brasil há vários anos. As propostas mais recentes de reforma têm como foco os tributos sobre bens e serviços, os chamados tributos indiretos, que respondem por $48 \%$ da carga tributária brasileira (Brasil 2010). De fato, a proposta de reforma tributária enviada pelo governo, em 2008, ao Congresso Nacional tem como pontos centrais a unificação de três tributos indiretos federais em um único tributo sobre o valor agregado e a uniformização nacional da legislação do principal tributo indireto brasileiro, o Imposto sobre Circulação de Mercadorias e Serviços de Comunicação e de Transporte Interestadual e Intermunicipal (ICMS). O objetivo principal dessa proposta é aumentar a eficiência do sistema tributário, mas sem reduzir a arrecadação. Ao mesmo tempo, o governo propõe rever a estrutura de alíquotas dos tributos indiretos de forma a tornar o sistema "mais justo e menos oneroso para a parcela mais pobre da população" (Brasil 2008). No entanto, como é bem conhecido da teoria da tributação ótima, há um forte conflito entre os objetivos de eficiência e de equidade em tributação (Diamond \& Mirrlees 1971, Deaton 1977). Em outras palavras, as estruturas de alíquotas mais desejáveis de acordo com critérios de equidade tendem a ser aquelas que geram as maiores perdas de eficiência, ao distorcer mais fortemente as escolhas de consumo das famílias.

Nesse contexto, cabe a pergunta: que bens são candidatos à redução de alíquota e que bens são candidatos ao aumento de alíquota, considerando objetivos de eficiência e equidade? O objetivo deste artigo é lançar alguma luz sobre essa questão, identificando direções de reforma na tributação indireta no Brasil que gerem um ganho de bem-estar para a sociedade, sem perda de arrecadação para governo. Para tanto, será usado o método desenvolvido por Ahmad \& Stern (1984), aplicado aos microdados da Pesquisa de Orçamentos Familiares (POF) 2002-2003. O método proposto por Ahmad \& Stern (1984) consiste em ordenar os diversos bens consumidos pelas famílias de acordo com o custo marginal social de sua tributação.

A abordagem de Ahmad \& Stern (1984) já foi aplicada para o Brasil por Sampaio de Souza (1996). Todavia, há pelo menos duas razões para novas estimativas. A primeira é a necessidade de atualização, já que Sampaio de Souza (1996) usa dados do Estudo Nacional de Despesa Familiar (ENDEF), de 1974/1975. A segunda motivação é o fato de Sampaio de Souza (1996) se basear em elasticidades da demanda derivadas do restritivo Sistema de Despesa Linear (Linear Expenditure System, LES). Há um resultado bem conhecido na literatura (Decoster \& Shokkaert 1990, Madden 1996) de que, apesar do ordenamento dos custos marginais sociais da tributação ser razoavelmente robusto com relação à escolha do sistema de demanda mais flexíveis, isso não se verifica com o LES, que impõe as propriedades de homogeneidade e simetria. Madden (1996), por exemplo, compara os ordenamentos produzidos pelo LES e por nove especificações mais flexíveis da demanda (envolvendo três diferentes modelos, cada um deles estimado para três diferentes especificações quanto às restrições impostas pela maximização de utilidade) e observa uma forte correlação entre todas as especificações com exceção do LES.

O uso do LES em estudos empíricos para o Brasil já foi ditado pela insuficiência de dados de preços para estimar um sistema de demanda mais flexível cobrindo todas as categorias de consumo. Atualmente, no entanto, há estimativas das elasticidades-preço próprias e cruzadas da demanda baseadas no 
flexível Sistema Quase Ideal de Demanda (Almost Ideal Demand System, AIDS), proposto por Deaton \& Muellbauer (1980). É o caso das elasticidades estimadas por Pintos-Payeras (2009), que serão utilizadas neste trabalho.

Outro estudo que cabe mencionar é Vélez et al. (2002), que também busca identificar, para o Brasil, direções de reforma na tributação indireta que gerem aumento de bem-estar social sem perda de receita para o governo. Todavia, esse estudo usa uma abordagem alternativa ao método de Ahmad \& Stern (1984), conhecida como abordagem "Daltoniana", que é baseada na dominância da curva de concentração de um bem em relação à curva de concentração de outro bem (ver, por exemplo, Mayshar \& Yitzhaki 1995). Como alerta Santoro (2007), nessa abordagem as estimativas precisas das elasticidades-preço (próprias e cruzadas) das demandas são bem mais importantes do que no modelo de Ahmad \& Stern (1984). Mesmo assim, Vélez et al. (2002) não oferece informação de como as elasticidades foram obtidas. Outro fator que limita a aplicação prática dos resultados de Vélez et al. (2002) é o fato de se basear em dados de despesa familiar apenas para as regiões metropolitanas.

Além desta introdução, o artigo está divido em quatro seções. A seção 2 descreve o modelo teórico usado para cálculo do custo marginal social da tributação. A seção 3 explica como os vários componentes do modelo foram obtidos para o Brasil. A seção 4 apresenta os resultados empíricos. A seção 5 conclui.

\section{Custo marginal social da tributação: teoria}

Em um artigo bastante influente, Ahmad \& Stern (1984) propuseram uma abordagem para análise de mudanças na tributação indireta que ficou conhecida na literatura como teoria das reformas tributárias marginais. ${ }^{1}$ Essa abordagem busca identificar direções de mudanças nas alíquotas tributárias sobre bens e serviços que aumentam o bem-estar social, sem reduzir a arrecadação. Para tanto, avalia-se para cada bem $i(i=1, \ldots, \mathrm{n})$ o custo marginal em termos de bem-estar social de arrecadar uma unidade extra de receita via um aumento da tributação do bem $i$. Se, por exemplo, tal custo marginal for maior para o bem $i$ do que para o bem $j$, então é possível aumentar o bem-estar social, sem reduzir a arrecadação, reduzindo a tributação do bem $i$ e aumentando a tributação do bem $j$. Obviamente, a possibilidade de tais reformas existe enquanto houver diferença entre os custos marginais sociais. Em outras palavras, quando esses custos são iguais para todos os bens, as alíquotas tributárias são ótimas.

No modelo padrão, a avaliação é baseada em uma função de bem-estar social $W=W\left(v^{1}, \ldots, v^{h}\right)$, em que $v=v^{h}\left(y^{h}, p\right)$ é a função utilidade indireta da família $h(h=1, \ldots, \mathrm{H})$, expressa em termos da despesa total $y$ e do vetor de preços $p$. Do lado da produção, os preços são fixos, de forma que alterações nos tributos indiretos são totalmente refletidas em alterações nos preços ao consumidor, ou seja, $d t_{i}=d p_{i}$, sendo $t_{i}$ o imposto sobre o bem $i .^{2}$

\footnotetext{
${ }^{1}$ Para uma resenha recente dessa literatura, ver Santoro (2007).

${ }^{2}$ Teoricamente, os preços do produtor são fixos apenas quando todos os bens são produzidos por firmas competitivas sob retornos constantes de escala (ver, por exemplo, Dixit (1975)). Todavia, devido à dificuldade de se obter evidência empírica sobre que o grau de transferência dos tributos (pelo menos num nível de desagregação setorial requerido para estudos de questões distributivas), a maioria dos estudos de incidência tributária tem se baseado na hipótese de transferência integral. Ahmad \& Stern (1991) lembram que em modelos não competitivos a
} 
O impacto de uma mudança no preço (tributação) do bem $i$ sobre o bemestar social pode ser definido como:

$$
\frac{\partial W}{\partial p_{i}}=\sum_{h} \frac{\partial W \partial v^{h}}{\partial v^{h} \partial p_{i}}
$$

Então, usando a identidade de Roy: ${ }^{3}$

$$
\frac{\partial W}{\partial p_{i}}=-\sum_{h} \beta^{h} x_{i}^{h}
$$

Em que $\beta^{h}=\frac{\partial W \partial v^{h}}{\partial v^{h} \partial y^{h}}$ é a utilidade marginal social da despesa total da família $h$ e $x_{i}^{h}$ é o consumo do bem $i$ pela família $h$. Os $\beta$ s na equação 2 são interpretados como pesos distributivos, ou pesos sociais, pois ponderam o consumo das famílias no cálculo do bem-estar social com relação à importância que a sociedade atribui a cada família.

A receita agregada da tributação de todos os $n$ bens, $R$, é dada por:

$$
R=\sum_{h} \sum_{i} t_{i} x_{i}^{h}=\sum_{i} t_{i} X_{i}
$$

sendo $X_{i}=\sum_{h} x_{i}^{h}$ o consumo agregado do bem $i$.

O impacto sobre a receita agregada de um aumento marginal na tributação do bem $i$ pode ser obtido diferenciando 3 com relação a $t_{i}$ :

$$
\frac{\partial R}{\partial t_{i}}=X_{i}+\sum_{j} t_{j} \frac{\partial X_{j}}{\partial t_{i}}
$$

Formalmente, o custo marginal social de um aumento na tributação do bem $i$, denotado por $\lambda_{i}$, é definido como a razão entre a redução marginal correspondente no bem-estar social e o aumento marginal correspondente da receita arrecadada:

$$
\lambda_{i}=-\frac{\partial W}{\partial t_{i}} / \frac{\partial R}{\partial t_{i}}
$$

em que o sinal negativo do lado direito da equação 5 serve para tornar o custo marginal social positivo, já que o numerador será sempre negativo e, em geral, o denominador é positivo. ${ }^{4}$ Como mencionado antes, se $\lambda_{i}>\lambda_{j}$, então o bemestar pode ser aumentado, mantendo-se a receita constante, via uma redução na tributação do bem $i$ e um aumento na tributação do bem $j$.

Usando as equações 2 e $4, \lambda_{i}$ pode ser reescrito como:

transferência pode ser acima de 100\%, de forma que a hipótese de transferência integral pode ser uma hipótese intermediária razoável sobre os efeitos redistributivos dos impostos, e não um caso extremo, como pode parecer.

${ }^{3}$ A Identidade de Roy estabelece uma ligação entre as demandas marshallianas, $x_{i}^{h}\left(y^{h}, p\right)$ e a função utilidade indireta, $v^{h}=v^{h}\left(y^{p}, p\right)$, dada por: $x_{i}^{h}\left(y^{h}, p\right)-\frac{\partial v^{h}}{\partial p_{i}} / \frac{\partial v^{h}}{\partial y^{h}}$

${ }^{4}$ Note que é possível que $\frac{\partial R}{\partial t_{i}}<0$, por exemplo, como resultado da combinação de uma elevada elasticidade-preço própria da demanda pelo bem $i$ e de uma alíquota tributária particularmente elevada sobre o bem $i$, fazendo com que a perda de receita devido à redução do consumo do bem $i$ não seja compensada pelo aumento de $t_{i}$ e/ou pelo aumento do consumo de outros bens tributados. 


$$
\lambda_{i}=\frac{\sum_{h} \beta^{h} x_{i}^{h}}{X_{i}+\sum_{j} t_{j}\left(\frac{\partial X_{j}}{\partial p_{i}}\right)}
$$

Multiplicando o numerador e o denominador da equação 6 por $p_{i}$, pode-se derivar uma expressão mais conveniente para estudos empíricos, envolvendo gastos (em vez de quantidades) e elasticidades-preço:

$$
\lambda_{i}=\frac{\sum_{h} \beta^{h} p_{i} x_{i}^{h}}{p_{i} X_{i}+\sum_{j} \tau_{j} \eta_{j i} p_{j} X_{j}}
$$

sendo $\eta_{j i}$ a elasticidade-preço da demanda agregada pelo bem $j$ com relação ao preço do bem $i, \frac{\partial X_{j} p_{i}}{\partial p_{i} X_{j}}$, e $\tau_{j}$ a alíquota tributária efetiva sobre o bem $j$ calculada como proporção do preço final deste bem. Note, portanto, que esta alíquota é calculada "por dentro", ou seja, incluindo o tributo na base de cálculo.

Fica transparente na equação 7, que o custo marginal social da tributação incorpora considerações de equidade e de eficiência: um bem consumido mais pesadamente por famílias com maior peso distributivo e com elasticidadepreço própria mais alta (em termos absolutos) gera um custo social mais alto quando é tributado.

\section{Calculando $\lambda_{i}$ para o Brasil}

A equação 7 mostra que o cálculo de $\lambda_{i}$ requer informação sobre os seguintes termos: (i) despesa de cada família com cada bem $\left(p_{i} x_{i}^{h}\right)$; (ii) despesa familiar agregada (isto é, do total de famílias) com cada bem $\left(p_{i} X_{i}\right)$; (iii) peso social de cada família $\left(\beta^{h}\right)$; (iv) elasticidades-preço da demanda agregada $\left(\eta_{j i}\right)$; e (v) alíquotas tributárias efetivas $\left(\tau_{i}\right)$. Neste estudo, os componentes (i) e (ii) são obtidos diretamente dos microdados da POF 2002-2003. O restante desta seção descreve a quantificação dos demais componentes.

\subsection{Os Pesos Sociais}

Seguindo Ahmad \& Stern (1984) e a maioria dos artigos empíricos sobre o tema, os pesos sociais neste artigo são derivados fazendo uso da seguinte função de bem-estar social:

$$
W=\sum_{h} \frac{\left(y^{h}\right)^{1-\varepsilon}}{1-\varepsilon}
$$

Em que $y^{h}$ é a despesa total per capita da família $h$ e $\varepsilon$ é um parâmetro que mede o grau de aversão à desigualdade. ${ }^{5}$ Isso implica que a utilidade marginal social da despesa da família $h$ é dada por:

$$
\beta^{h}=\frac{\partial W}{\partial y^{h}}=\left(y^{h}\right)^{-\varepsilon}
$$

\footnotetext{
${ }^{5}$ Para $\varepsilon=1, W=\sum_{h} \ln \left(y^{h}\right)$.
} 
Como apenas os valores relativos de $\beta^{h}$ interessam na análise de reformas tributárias marginais, é conveniente impor a normalização $\beta^{1}=\left(y^{1}\right)^{-\varepsilon}=1$, sendo $\beta^{1}$ o peso social da família mais pobre, e reescrever:

$$
\beta^{h}=\left(\frac{y^{1}}{y^{h}}\right)^{\varepsilon}
$$

Quanto maior o valor de $\varepsilon$, maior o peso relativo da família mais pobre. Assim, por exemplo, se $\varepsilon=0, \beta^{h}=1$ para todo $h$, e nenhuma importância é dada à questão distributiva. Se $\varepsilon=1$, então uma família com o dobro da despesa per capita da família mais pobre terá um peso social igual à metade do peso desta última.

Neste artigo, os $\beta$ s são calculados para cada família a partir da equação 10 usando os microdados da POF 2002-2003 e valores alternativos para o parâmetro de aversão à desigualdade no intervalo de 0 a 3 . A variável utilizada é a despesa total de consumo das famílias (em termos per capita), monetária e não-monetária. ${ }^{6}$ A Figura 1 dá uma ideia de como os pesos sociais estimados caem à medida que a despesa familiar per capita aumenta. Ele mostra, para diferentes valores de $\varepsilon$, o peso social médio por décimos de despesa, com as famílias ordenadas pela despesa total per capita. Observe-se que um parâmetro de aversão à desigualdade igual a três já representa um alto grau de aversão à desigualdade, atribuindo pesos significativamente diferentes de zero apenas para as famílias no primeiro décimo de despesa familiar per capita (10\% mais pobres). ${ }^{7}$

\subsection{Elasticidades-preço}

As elasticidades-preço próprias e cruzadas da demanda foram obtidas através de Pintos-Payeras (2009). Esse autor estimou as elasticidades não-compensadas (ou marshallianas) para 27 grupos de produtos, a partir dos microdados da POF 2002-2003. O sistema de demanda utilizado foi o Sistema Quase Ideal de Demanda (AIDS). Ressalte-se que, dada a restrição de dados de preços no Brasil, a estimação do AIDS foi realizada com base em observações de preço e consumo apenas para as onze regiões metropolitanas incluídas no cômputo do Índice Nacional de Preços ao Consumidor Amplo (IPCA).

Assim, no presente estudo, utilizam-se elasticidades-preço estimadas para as regiões metropolitanas como proxies para as elasticidades-preço das demandas (agregadas) no Brasil como um todo. Vale salientar que a importância das elasticidades na determinação do ordenamento dos bens de consumo de acordo com os custos marginais sociais da tributação $\left(\lambda_{i}\right)$ diminui à medida que o grau de aversão à desigualdade $(\varepsilon)$ aumenta. Como será visto na seção 4, para valores médios e altos de aversão à desigualdade, o ordenamento dos bens é determinado essencialmente por suas características distributivas, captadas pelo numerador da equação 7 , e não pelas elasticidades.

\footnotetext{
${ }^{6}$ Para algumas famílias, a POF reporta despesa total de consumo (monetária e não-monetária) baixa demais. Para tentar atenuar o problema de subestimação, igualamos a $R \$ 30,00$ ( $\mathrm{R} \$ 1,00 /$ dia $)$ a despesa total per capita mensal de toda família com despesa total per capita inferior a esse valor (ressalte-se que isso ocorreu para menos de $1 \%$ do total de famílias). Isso significa que os pesos sociais foram calculados supondo que as famílias mais pobres têm despesa total per capita igual a $\mathrm{R} \$ 30,00$ por mês.

${ }^{7}$ Valores acima de 3 se aproximam da visão Rawlsiana em que apenas o bem-estar da família mais pobre é levado em consideração.
} 


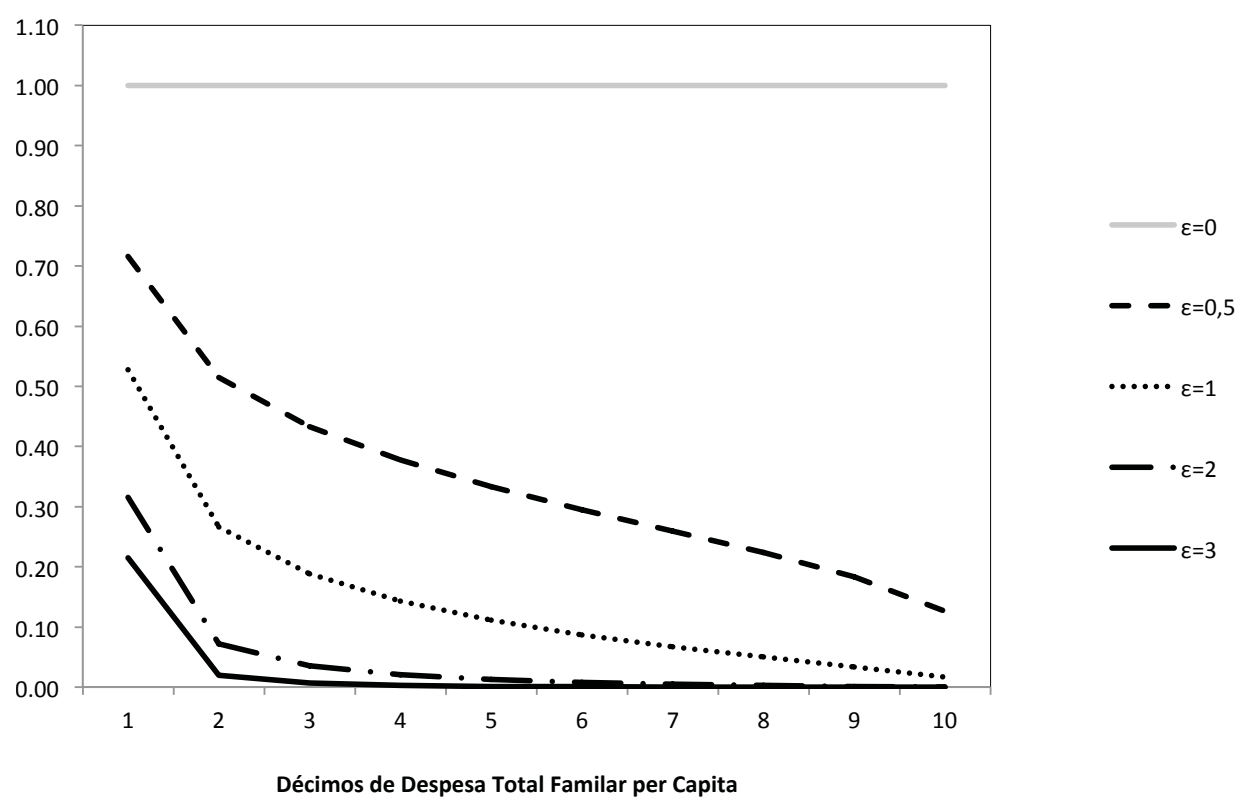

Fonte: POF 2002-03, Pintos-Payeras e cálculo dos autores.

Figura 1: Peso Social Médio por Decil

Para poder usar essas elasticidades, o presente estudo procurou classificar, a partir dos microdados da POF, os bens e serviços consumidos pelas famílias nos 27 grupos de Pintos-Payeras (2009). Os nomes dos grupos, no entanto, foram mudados buscando torná-los mais informativos. A Tabela A.2 do apêndice reproduz integralmente as informações de Pintos-Payeras (2009) sobre a composição de cada grupo, bem como mostra a correspondência com os nomes adotados neste artigo. Ressalte-se que, seguindo Pintos-Payeras, o presente estudo procurou incluir apenas itens de despesa para os quais há informação de preço disponível. ${ }^{8}$ Em Pintos-Payeras a soma das despesas com esses itens representa $65 \%$ da despesa total das famílias residentes nas regiões metropolitanas. Neste trabalho, a despesa com os 27 grupos de produtos representa $68 \%$ da despesa total das famílias no Brasil.

\subsection{Alíquotas Tributárias Efetivas}

A tributação indireta no Brasil consiste de um conjunto extremamente complexo de tributos que usam diferentes bases tributárias e alíquotas, e, em grande medida, incidem sobre insumos. Assim, o efeito final desses tributos sobre os preços pagos pelas famílias é obscuro, dependendo não apenas da medida em que são repassados para frente em cada estágio da cadeia de produção e circulação, mas também da estrutura precisa das transações interindustriais. Como resultado, as alíquotas tributárias efetivas sobre o consumidor final podem divergir consideravelmente das alíquotas legais (ou nominais). Na análise de reformas tributárias marginais o conceito relevante é o de alíquota tributária efetiva.

\footnotetext{
${ }^{8}$ Disponível na POF ou na tabela de preços dos produtos usados no cálculo do IPCA, disponibilizada eletronicamente em: ftp://ftp.ibge.gov.br/Precos_Indices_de_Precos_ao_Consumidor/Precos_Medios /Nao_Alimenticios_09_1999.zip
} 
A alíquota efetiva para cada um dos 27 bens compostos desse artigo foi estimada a partir de Siqueira et al. (2011), que calculou a alíquota tributária efetiva sobre cada um dos 110 produtos discriminados na Matriz de InsumoProduto do Brasil. O método utilizado por Siqueira et al. (2011) foi proposto por Scutella $(1997,2002)$, e já foi aplicado para o Brasil por Siqueira et al. (2002). Sendo baseado na matriz de insumo-produto, o método permite captar os efeitos da tributação direta e indireta de insumos. Por exemplo, no caso da tributação de gasolina, é possível levar em conta tanto os efeitos diretos sobre o preço do transporte, quanto os efeitos indiretos quando o transporte é utilizado como insumo. O cálculo das alíquotas efetivas parte da receita tributária efetivamente arrecadada pelo governo de cada setor de atividade, e então supõe que os tributos são totalmente transferidos para frente em cada estágio da cadeia de produção, até o consumidor final. Dessa forma, o cálculo incorpora as interdependências que resultam das transações intersetoriais e leva em conta o efeito cumulativo de alguns tributos, bem como a evasão fiscal.

As alíquotas efetivas no presente estudo incorporam todos os tributos indiretos que constam na Matriz de Insumo-Produto do Brasil para 2005 (IBGE 2008), a saber: Imposto sobre a Circulação de Mercadorias e sobre Serviços de Transporte Interestadual e Intermunicipal e de Comunicação (ICMS), Imposto sobre Produtos Industrializados (IPI), Imposto de Importação (II), e uma categoria que o IBGE denomina 'outros impostos menos subsídios', a qual inclui a Contribuição para Financiamento da Seguridade Social (COFINS), a Contribuição para o Programa de Integração Social (PIS), o Imposto sobre Serviços de Qualquer Natureza (ISS), a CIDE-Combustíveis e o Imposto sobre Operações Financeiras (IOF).

Cabe dizer que a compatibilização entre os grupos de produtos da Matriz e os grupos deste trabalho foi feita a partir de um nível de desagregação bastante elevado: 110 produtos na Matriz e 67 subitens dos grupos de produtos aqui reportados. Ressalte-se que os 67 subgrupos foram construídos levandose em conta tanto a necessidade de compatibilização com a Matriz quanto a existência de tratamento tributário diferenciado. Esse procedimento facilitou consideravelmente a conciliação dos grupos e reduziu a arbitrariedade no cálculo das alíquotas efetivas médias.

Para auxiliar na compreensão dos resultados, a Tabela 1 sintetiza informações sobre a estrutura de consumo das famílias, as elasticidades-preço da demanda e as alíquotas efetivas. ${ }^{9}$

\section{Resultados}

O custo marginal social da tributação, $\lambda$, para cada um dos 27 grupos de produtos foi calculado para cinco valores do parâmetro de aversão à desigualdade, $\varepsilon(0 ; 0,5 ; 1 ; 2$ e 3$)$. Os resultados são apresentados na Tabela 2 , que mostra também o ranking dos produtos de acordo $\operatorname{com} \lambda$, dos valores mais altos para os mais baixos. Dessa forma, o ranking indica quais produtos são os melhores candidatos para redução de alíquota. ${ }^{10}$

Em primeiro lugar, cabe observar que o grupo bebidas alcoólicas não foi incluído nessa tabela. Isso porque os $\lambda$ s obtidos para esse grupo têm sinal negativo, requerendo interpretação à parte. $\mathrm{O}$ sinal negativo ocorre porque $\mathrm{o}$

\footnotetext{
${ }^{9}$ A matriz completa de elasticidades-preço é apresentada em Pintos-Payeras (2009).

${ }^{10}$ Note que os produtos estão listados de acordo com o ranking em $\varepsilon=1$.
} 


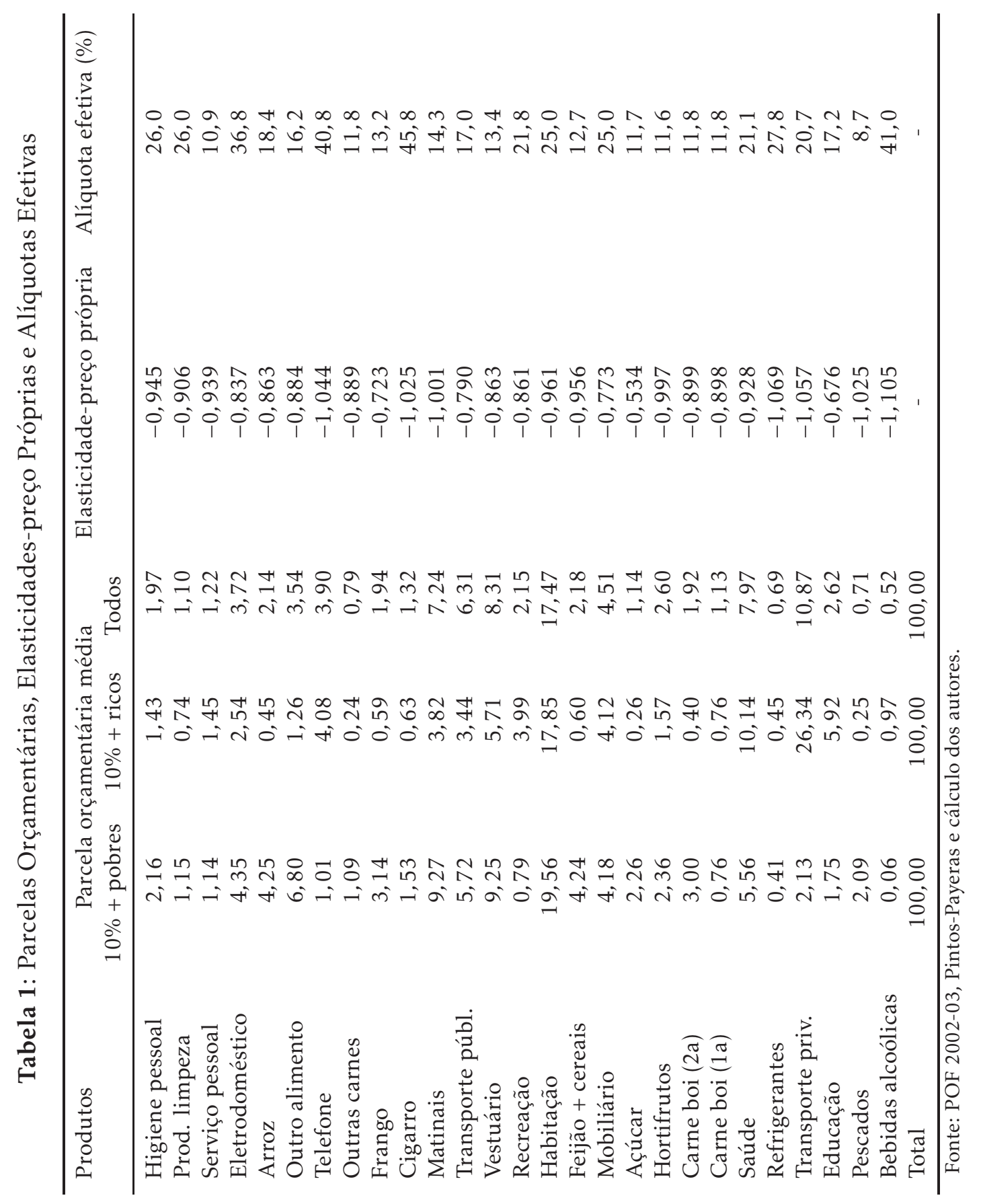


denominador da equação 7 é negativo para bebidas alcoólicas, ou seja, um aumento na alíquota tributária sobre bebidas alcoólicas reduz a arrecadação do governo. ${ }^{11}$ Isso resulta da combinação de uma alta elasticidade-preço própria $\left(\left|\eta_{i i}\right|>1\right)$ e uma alíquota efetiva extremamente elevada, de forma que a perda de receita devido à redução do consumo de bebidas alcoólicas não é compensada pelo aumento do consumo de outros produtos tributados. Portanto, neste caso, identifica-se uma mudança tributária capaz de produzir uma melhora Paretiana no bem-estar social: uma redução na alíquota de bebidas alcoólicas aumenta o bem-estar dos consumidores e ainda gera receita extra para o governo. Deve-se ressaltar, no entanto, que esta análise ignora os efeitos externos negativos associados ao consumo de bebidas alcoólicas.

A Tabela 2 mostra que há outros três grupos de produtos que também são fortes candidatos a redução de alíquota tanto por critérios de eficiência quanto de equidade, a saber: produtos de higiene, produtos de limpeza e eletrodomésticos. Observe que os custos sociais da tributação desses itens estão entre os mais altos para todos os níveis de aversão à desigualdade. De fato, a Tabela 1 mostra que, enquanto esses produtos têm peso maior no orçamento das famílias mais pobres, suas alíquotas efetivas estão entre as mais elevadas. Note-se que, arroz e o grupo outros alimentos também se posicionam (e se mantém) no topo da lista de candidatos a redução de alíquota já a partir de um baixo grau de aversão à desigualdade $(\varepsilon=0,5)$. No entanto, quando apenas eficiência é levada em consideração $(\varepsilon=0)$, esses itens podem ser considerados candidatos a aumento de alíquota.

Ao contrário, o grupo refrigerantes destaca-se como candidato ao aumento de alíquota para todos os valores de $\varepsilon$, e transporte privado e educação estão entre os principais alvos para aumento de alíquota já a partir de $\varepsilon=0,5 .{ }^{12}$ No caso de transporte privado e de educação, isso reflete o fato de suas participações na despesa das famílias aumentarem significativamente com o aumento da despesa total (ver Tabela 1). Ao também encontrar um baixo custo social para tributação de educação no Japão e na Coreia, Urakawa \& Oshio (2010) chama a atenção para o fato de que o financiamento (indireto) da escola pública pelas famílias, via tributos, não consta nos dados de despesas das famílias, mas apenas as despesas com escola privada. Além disso, o valor social da educação é subestimado porque a análise ignora os efeitos externos positivos da educação. No caso de transporte privado, no entanto, a incorporação dos efeitos externos associado ao seu uso (poluição e congestionamento) reforçaria o argumento para aumento da tributação.

Por outro lado, pode-se observar na Tabela 2 que para alguns produtos há um forte conflito entre objetivos de equidade e de eficiência na tributação. Destacam-se entre esses o grupo feijão e outros cereais, açúcar e frango, os quais ficam entre os principais candidatos ao aumento de alíquota no caso de nenhuma ou pouca aversão à desigualdade, e entre os principais candidatos à redução de alíquota quando há forte aversão à desigualdade $(\varepsilon=2$ ou 3$)$. Uma

\footnotetext{
${ }^{11}$ Nesse caso, diz-se que a alíquota encontra-se do lado direito da chamada curva de Laffer, que é a representação teórica da relação entre a receita arrecadada pelo governo e a alíquota do imposto, e tem forma de U invertido.

${ }^{12}$ Vélez et al. (2002) identificaram transporte privado como o principal candidato ao aumento de imposto e um grupo denominado 'despesas pessoais' como o principal candidato a redução de imposto, o que é consistente com os resultados do presente estudo quando há alguma aversão à desigualdade. Cabe ressaltar que o fato desses autores trabalharem com um nível de agregação de produtos bem mais elevado (7 grupos) do que neste estudo impede outras comparações.
} 


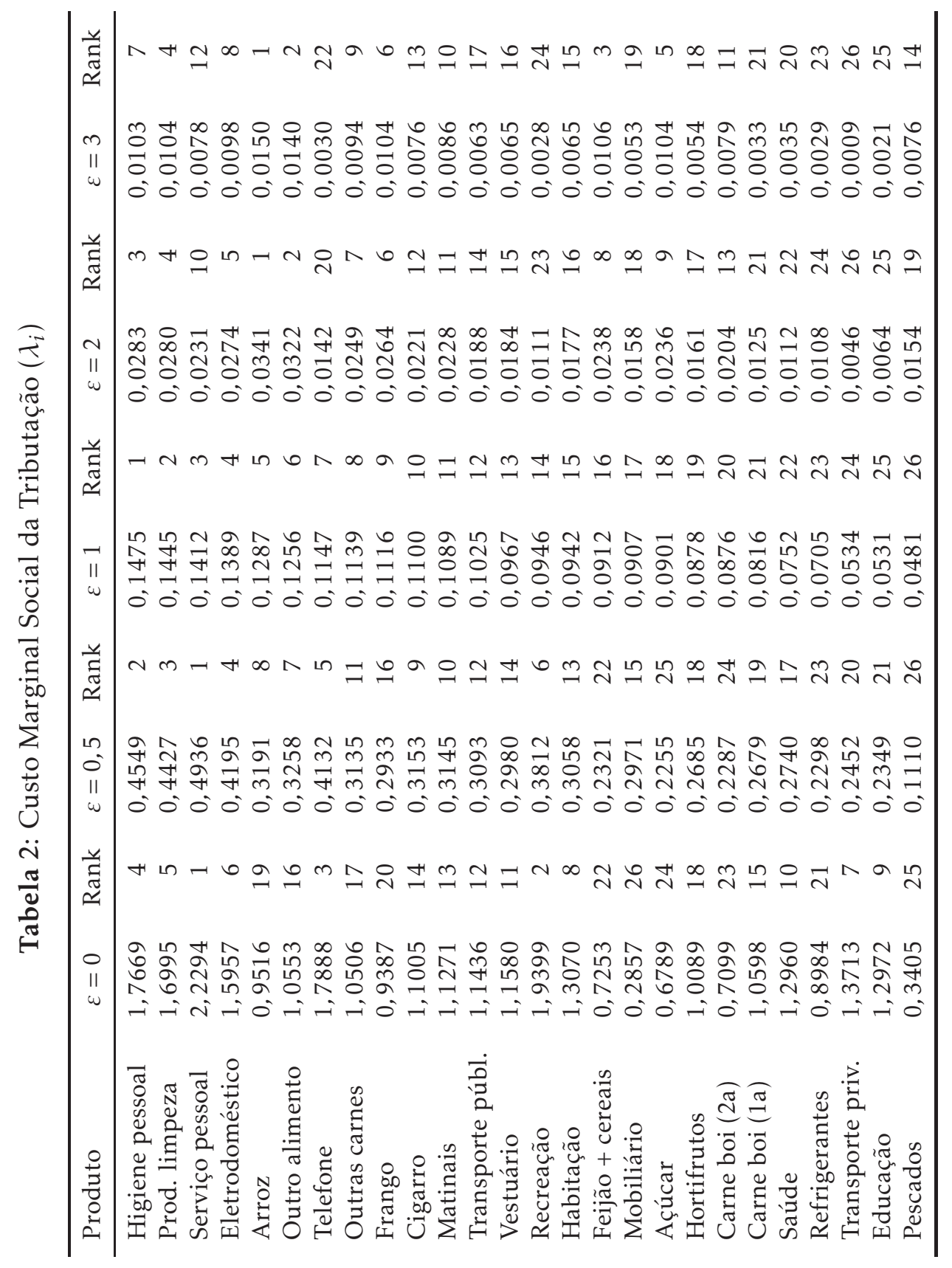


situação inversa ocorre com o grupo recreação e com telefone, cujos custos sociais reduzem drasticamente à medida que o grau de aversão à desigualdade aumenta. ${ }^{13}$

De fato, a Tabela 3 mostra que o coeficiente de correlação de ranking dos produtos entre o caso de nenhuma aversão à desigualdade $(\varepsilon=0)$ e o caso de alta aversão à desigualdade $(\varepsilon=2$ ou 3$)$ é negativo, indicando que, no geral, há uma inversão na posição dos bens. Por outro lado, a correlação de ranking se torna bastante elevada para valores médios e altos de aversão à desigualdade, uma vez que o custo social se torna crescentemente dominado por considerações de equidade.

Tabela 3: Coeficiente de Correlação de Ranking (Spearman)

\begin{tabular}{lrrlll}
\hline & $\varepsilon=0$ & $\varepsilon=0,5$ & $\varepsilon=1$ & $\varepsilon=2$ & $\varepsilon=3$ \\
\hline$\varepsilon=0$ & 1 & & & & \\
$\varepsilon=0,5$ & 0,706 & 1,000 & & & \\
$\varepsilon=1$ & 0,436 & 0,892 & 1 & & \\
$\varepsilon=2$ & $-0,077$ & 0,478 & 0,789 & 1 & \\
$\varepsilon=3$ & $-0,243$ & 0,282 & 0,623 & 0,954 & 1 \\
\hline
\end{tabular}

\section{Conclusões}

Este artigo aplicou o método desenvolvido por AAhmad \& Stern (1984) para calcular o custo marginal social da tributação para 27 grupos de bens, usando a POF 2002-2003 e elasticidades-preço da demanda baseadas no AIDS (estimadas por Pintos-Payeras 2009). Os cálculos foram realizados para diferentes hipóteses sobre o grau de aversão da sociedade à desigualdade.

Os resultados sugerem que a forma mais eficiente de aumentar a equidade da tributação indireta no Brasil seria reduzindo as alíquotas tributárias sobre bebidas alcoólicas, produtos de limpeza, produtos de higiene pessoal e eletrodomésticos, e aumentando as alíquotas de transporte privado, refrigerantes e educação. Ressalvas são feitas para o fato da análise não levar em conta os efeitos externos associados a bebidas alcoólicas e educação. Por outro lado, observou-se uma correlação negativa entre os rankings dos bens e serviços para o caso em que apenas eficiência importa e o caso em que há forte aversão à desigualdade. Isso indica que, em geral, há um forte conflito entre objetivos de equidade e eficiência na reforma da tributação indireta no Brasil.

Cabe lembrar que a análise aqui desenvolvida trata de reformas marginais, ou seja, pequenas mudanças a partir do status quo. A análise dos efeitos de reformas substanciais na tributação requer a estimação de mudanças na demanda e no bem-estar de diferentes famílias para pontos distantes da posição corrente, e não apenas informação sobre a resposta agregada (ou média) a alterações marginais nos preços.

\footnotetext{
${ }^{13}$ Sabe-se que o acesso das classes de renda mais baixa ao telefone aumentou consideravelmente nos últimos anos, o que pode ter elevado o custo marginal social da tributação deste setor. Cabe ressaltar, no entanto, que isso depende fundamentalmente da forma como o aumento da despesa das famílias com telefone foi distribuído entre as diferentes classes de renda.
} 


\section{Referências Bibliográficas}

Ahmad, E. \& Stern, N. H. (1984), 'The theory of reform and indian indirect taxes', Journal of Public Economics 25(3), 259-298.

Ahmad, E. \& Stern, N. H. (1991), The Theory and Practice of Tax Reform in Developing Countries, Cambridge University Press.

Brasil, M. d. F. (2008), 'Reforma tributária', Brasília. Disponível em http://www.fazenda.gov.br/portugues/documentos/2008/fevereiro/Cartilha-Reforma-Tributaria.pdf.

Brasil, S. d. R. F. (2010), 'Carga tributária no brasil 2009: Análise por tributos e bases de incidência', Estudos Tributários, Brasília. Estudos Tributários no. 21.

Deaton, A. (1977), 'Equity, efficiency, and the structure of indirect taxation', Journal of Public Economics 8(3).

Deaton, A. \& Muellbauer, J. (1980), 'An almost ideal demand system', American Economic Review 70(3), 312-326.

Decoster, A. \& Shokkaert, E. (1990), 'Tax reform results with different demand systems', Journal of Public Economics 41(3), 277-296.

Diamond, P. \& Mirrlees, J. (1971), 'Optimal taxation and public production i: Production efficiency', American Economic Review 61(1), 8-27.

Dixit, A. (1975), 'Welfare effects of tax and price changes', Journal of Public Economics 26(3-4), 103-123.

IBGE (2008), 'Matriz de insumo-produto: Brasil 200/2005', Rio de Janeiro. Série Contas Nacionais.

Madden, D. (1996), 'Marginal tax reform and the specification of consumer demand systems', Oxford Economic Papers 48(4), 556-567.

Mayshar, J. \& Yitzhaki, S. (1995), 'Dalton-improving indirect tax reforms', American Economic Review 48(4), 793-808.

Pintos-Payeras, J. A. (2009), 'Estimação do sistema quase ideal de demanda para uma cesta ampliada de produtos empregando dados da pof de 20022003', Economia Aplicada 13(2), 231-255.

Sampaio de Souza, M. C. (1996), 'Tributação indireta no brasil: Eficiência versus equidade', Revista Brasileira de Economia 50(1), 3-20.

Santoro, A. (2007), 'Marginal commodity tax reforms: A survey', Journal of Economic Surveys 21(4), 827-848.

Scutella, R. (1997), 'The final incidence of australian indirect taxes', Melbourne Institute Working Paper, Melbourne. Working Paper No. 18/97s.

Scutella, R. (2002), 'The final incidence of australian indirect taxes', Australian Economic Review 32(4), 349-368. 
Siqueira, R. B., Nogueira, J. R. \& Souza, E. A. (2002), 'A incidência final dos impostos indiretos no brasil: Efeitos da tributação de insumos', Revista Brasileira de Economia 55(4), 53-76.

Siqueira, R. B., Nogueira, J. R. \& Souza, E. A. (2011), 'Alíquotas efetivas e a distribuição da carga tributária indireta entre as famílias no brasil', XV Prêmio do Tesouro Nacional 2010, Secretaria do Tesouro Nacional, Brasília. URL: Disponivel em http://www.tesouro.fazenda.gov.br/Premio_TN/XVPremio/financas/MHtefpXVPTN/Tema_4_MH.pdf

Urakawa, K. \& Oshio, T. (2010), 'Comparing marginal commodity tax reforms in japan and korea', Journal of Asian Economics 21(6), 579-592.

Vélez, C. E., Vianna, S. W., Silveira, F. G. \& Magalhães, L. C. (2002), Indirect taxation reform: searching for dalton-improvements in brazil, in T. W. Bank, ed., 'Inequality and Economic Development in Brazi', Vol. 1, The World Bank.

\section{Apêndice A}




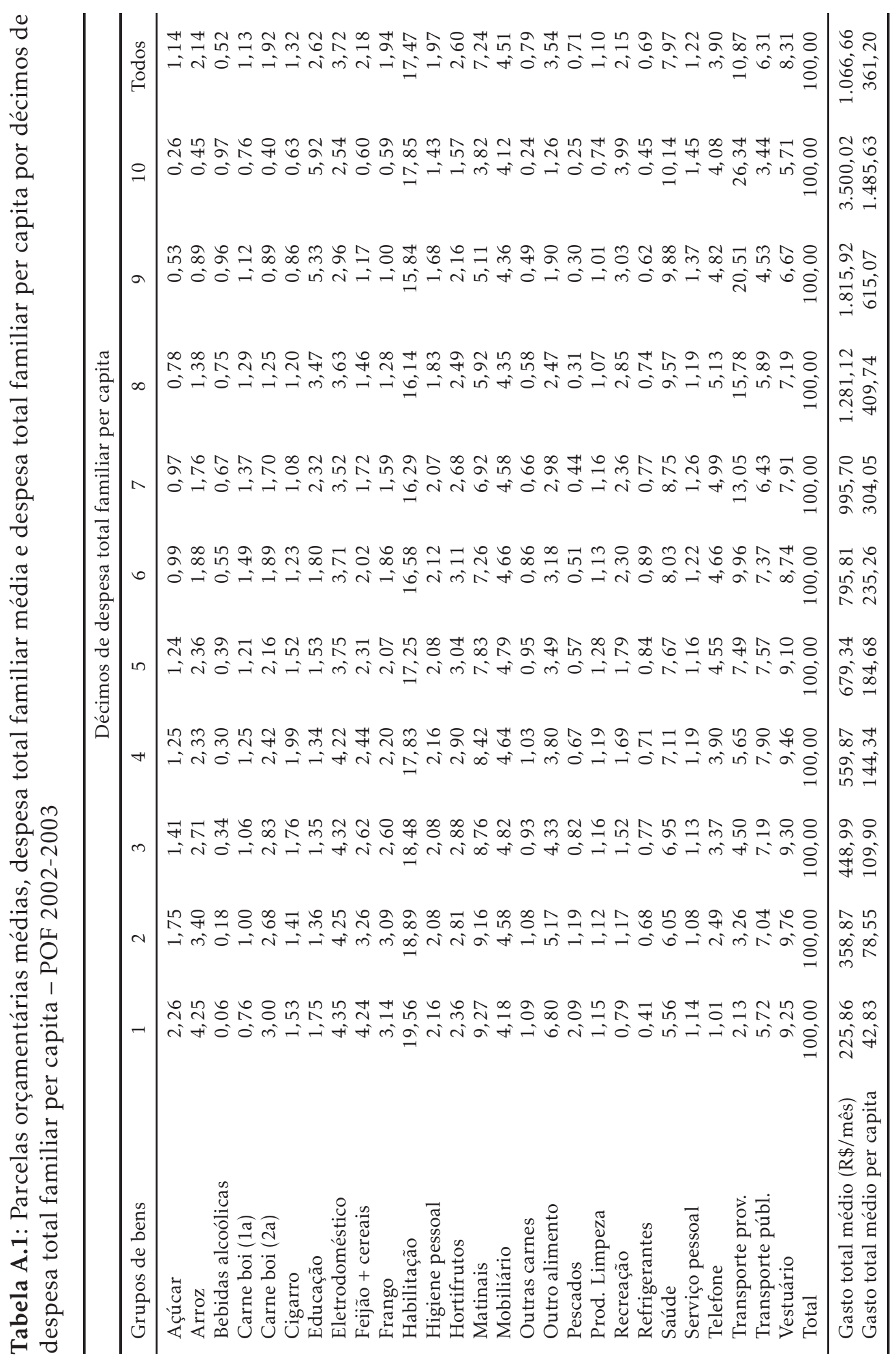


Tabela A.2: Descrição dos grupos de produtos

\begin{tabular}{|c|c|c|}
\hline Produto & Pintos-Payeras & Descrição \\
\hline Higiene pessoal & HIGIE & $\begin{array}{l}\text { Higiene: Sabonete, produtos para cabelo, pasta de } \\
\text { dente, desodorante, etc.; }\end{array}$ \\
\hline Prod. Limpeza & LIMP & $\begin{array}{l}\text { Produtos de limpeza: água sanitária, álcool, deter- } \\
\text { gente, sabão, entre outros; }\end{array}$ \\
\hline Serviço pessoal & SERV & $\begin{array}{l}\text { Serviços Pessoais: Costureira, manicure, cabelei- } \\
\text { reiro, cartório, entre outros. }\end{array}$ \\
\hline Eletrodoméstico & ELET & $\begin{array}{l}\text { Fogão, refrigerador, condicionador de ar, máquina } \\
\text { de lavar roupas, lâmpada, etc.; }\end{array}$ \\
\hline Arroz & ARRO & Todos os tipos de arroz; \\
\hline Outro alimento & PRALI & $\begin{array}{l}\text { Ovo de galinha, macarrão, farinha de trigo, fari- } \\
\text { nha de mandioca, enlatados, maionese, sal refi- } \\
\text { nado, óleo de soja, alimentos preparados, outros } \\
\text { açúcares, etc; }\end{array}$ \\
\hline Telefone & $\mathrm{COM}$ & Telefone fixo, tel. celular e tel. público (impulsos); \\
\hline Outras carnes & OCAR & $\begin{array}{l}\text { Outras Carnes: carne de suíno, ovos e carnes de } \\
\text { outras aves e carnes exóticas; }\end{array}$ \\
\hline Frango & FRAN & $\begin{array}{l}\text { Todos os produtos e subprodutos da carne de } \\
\text { Frango; }\end{array}$ \\
\hline Cigarro & CIGA & Cigarro. \\
\hline Matinais & MATI & $\begin{array}{l}\text { Matinais: Todos os laticínios, café, pães, e biscoi- } \\
\text { tos; }\end{array}$ \\
\hline Transporte públ. & TPÚB & $\begin{array}{l}\text { Transporte público: ônibus urbano, intermunici- } \\
\text { pal e interestadual, táxi, metrô, avião, etc; }\end{array}$ \\
\hline Vestuário & VEST & $\begin{array}{l}\text { Vestuário: calça comprida, agasalho, bermuda, ca- } \\
\text { miseta, saia, fralda, calçados, etc.; }\end{array}$ \\
\hline Recreação & RECR & $\begin{array}{l}\text { Jogos lotéricos, cinema, teatro, show, brinquedos, } \\
\text { produtos para animais, etc.; }\end{array}$ \\
\hline Habitação & HABI & Aluguel, condomínio, água e esgoto, entre outros; \\
\hline Feijão + cereais & OCER & $\begin{array}{l}\text { Outros Cereais: Feijão, aveia, cevada, milho, trigo } \\
\text { em grão, amendoim, etc. }\end{array}$ \\
\hline Mobiliário & MOVL & $\begin{array}{l}\text { Mobiliário e artigos do lar: móveis de sala, cozi- } \\
\text { nha, quarto, roupa de cama, etc.; }\end{array}$ \\
\hline Açúcar & AÇUC & Composto por açúcar refinado e açúcar cristal; \\
\hline Hortifrutos & HORT & Legumes, Verduras, Frutas, Tubérculos e Raízes; \\
\hline Carne boi (2a) & CAR2 & Carne de boi de segunda; \\
\hline Carne boi (1a) & CAR1 & Carne de boi de primeira; \\
\hline Saúde & SAÚD & $\begin{array}{l}\text { Saúde: plano de saúde, remédios, consulta médica } \\
\text { e odontológica, exames laboratoriais, óculos, etc.; }\end{array}$ \\
\hline Refrigerantes & REFRI & $\begin{array}{l}\text { Refrescos: Refrigerante, água de coco, guaraná em } \\
\text { pó, caldo decana, etc.; }\end{array}$ \\
\hline Transporte priv. & TPRI & $\begin{array}{l}\text { Transporte privado: automóvel novo, combustível, } \\
\text { óleo, pneu, conserto, etc.; }\end{array}$ \\
\hline Educação & EDUC & $\begin{array}{l}\text { Educação: cursos regulares, livros, jornal, revista, } \\
\text { caderno e artigos de papelaria; }\end{array}$ \\
\hline Pescados & PEIXE & Engloba todos os peixes e frutos do mar; \\
\hline Bebidas alcoólicas & ETÍLI & Bebidas alcoólicas. \\
\hline
\end{tabular}

Fonte: Pintos-Payeras (2009). Elaboração própria. 